C2018, Elsevier. Licensed under the Creative Commons Attribution-NonCommercialNoDerivatives 4.0 International http://creativecommons.org/about/downloads

(c) $\oplus \Theta \Theta$ 
Family incivility, emotional exhaustion at work, and being a good soldier: The buffering roles of waypower and willpower

\author{
Dirk De Clercq \\ Goodman School of Business \\ Brock University \\ St. Catharines, Ontario L2S 3A1 \\ ddeclercq@brocku.ca \\ Inam UI Haq \\ Lahore Business School \\ The University of Lahore \\ Lahore, Pakistan \\ inamulhaq27@gmail.com \\ Muhammad Umer Azeem \\ School of Business and Economics \\ University of Management and Technology \\ Lahore, Pakistan \\ umer.azeem@umt.edu.pk \\ Usman Raja \\ Goodman School of Business \\ Brock University \\ St. Catharines, Ontario L2S 3A1 \\ uraja@brocku.ca
}

Paper accepted for Journal of Business Research

April 2, 2018 


\title{
Family incivility, emotional exhaustion at work, and being a good soldier: The buffering roles of waypower and willpower
}

\begin{abstract}
This study unpacks the relationship between family incivility and organizational citizenship behavior (OCB), suggesting a mediating role of emotional exhaustion and moderating roles of waypower and willpower, two critical dimensions of hope. Three-wave data from employees and their peers in Pakistani organizations show that an important reason that family incivility diminishes OCB is that employees become emotionally overextended by their work. Employees’ waypower and willpower buffer this harmful effect of family incivility on emotional exhaustion though, such that this effect is mitigated when the two personal resources are high. The study also reveals the presence of moderated mediation, such that the indirect effect of family incivility on OCB through emotional exhaustion is weaker for employees high in waypower and willpower. For organizations, this study accordingly identifies a key mechanism by which family adversity can undermine voluntary behaviors; this mechanism is less forceful among employees who are more hopeful though.
\end{abstract}

Keywords: organizational citizenship behavior, family incivility, emotional exhaustion, waypower, willpower, conservation of resources theory 


\section{Introduction}

Previous studies emphasize the need to examine ways to stimulate employees’ propensity to undertake organizational citizenship behaviors (OCB), positive work behaviors that are not required by formal job descriptions, often referred to as being a "good soldier” (Organ, 1988; Podsakoff, MacKenzie, Paine, \& Bachrach, 2000). Such behaviors benefit both organizations and employees, because when employees engage in voluntary work efforts, they improve their organizations’ well-being and competitive advantage (Podsakoff, Whiting, Podsakoff, \& Blume, 2009) and also improve their own position, in that their performance appraisals often are based on such efforts (Lievens, De Corte, \& Schollaert, 2008). Although OCB sometimes entails helping behaviors targeted at individual members, which can contribute to organizational wellbeing indirectly (Deckop, Cirka, \& Andersson, 2003), the focus of the current study is on voluntary work behaviors that contribute to the organization directly, such as work attendance above the norm, voluntary adherence to informal rules that increase organizational effectiveness, and a strict focus on job-related issues instead of personal matters during work hours (Spitzmuller, Van Dyne, \& Ilies, 2008; Williams \& Anderson, 1991). In light of the positive outcomes of OCB, previous studies examine a plethora of enabling factors, such as transformational leadership (López-Domínguez, Enache, Sallan, \& Simo, 2013), perceived organizational justice (Cohen-Charash \& Spector, 2001), constructive feedback (Sommer \& Kulkarni, 2012), and positive job attitudes (Bowling, Wang, \& Li, 2012).

Despite the many positive consequences of OCB, such behavior does not emerge automatically but instead requires significant personal investments of time and energy (Quinn, Spreitzer, \& Lam, 2012; Trougakos, Beal, Cheng, Hideg, \& Zweig, 2015). Notable in this regard is that employees’ exposure to stressful situations may deplete their energy resources that 
otherwise would be available for OCB (Hobfoll, 1989). Accordingly, previous studies show how negative work conditions, such as role stress (Eatough, Chang, Miloslavic, \& Johnson, 2011; Rodell \& Judge, 2009), work overload and interpersonal conflict (Pooja, De Clercq, \& Belausteguigoitia, 2016), despotic leadership (Naseer, Raja, Syed, Donia, \& Darr, 2016), and psychological contract violations (Priesemuth \& Taylor, 2016), might steer employees away from OCB. Relatively less research investigates how OCB can be inhibited by stressful situations outside the workplace though, with the exception of research on the harmful effect of family-towork conflict (Amstad, Meier, Fasel, Elfering, \& Semmer, 2011). This oversight is important; to the extent that hardships experienced at home negatively interfere with organizational functioning, employees' propensity to allocate resources to voluntary activities may be thwarted (Leiter \& Durup, 1996). Discretionary work efforts that are not formally required usurp significant energy resources (Podsakoff et al., 2009), so investigating how and when energydepleting family conditions might turn employees away from OCB is critical for both scholars and practitioners.

A potential source of stress from outside the workplace is family incivility, or the extent to which employees are victims of rude and disrespectful behaviors by other family members (Lim \& Tai, 2014). Family incivility can come in different shapes, such as when people are ridiculed by family members, receive demeaning remarks, or are simply ignored. Research attention to family incivility is scarce, yet its presence is a significant concern for many organizations, due to its tendency to compromise productive work outcomes (Bai, Lin, \& Wang, 2016; Lim \& Tai, 2014). Contrary to incivility that takes place within the workplace-which is governed by written procedures and sanctions-incivility at home tends to be more covert and implicit and therefore particularly emotionally draining for employees (Lim \& Tai, 2014). 
Previous studies address how family incivility might undermine job performance (Lim \& Tai, 2014) and spur deviant work behavior (Bai et al., 2016) but not how this personal stressor might steer employees away from OCB or which factors explain or influence this process. This study seeks to address these gaps.

In particular, we propose that family incivility leads to lower OCB because the precarious situation makes employees feel emotionally overextended (Maslach, 1993). This emotional exhaustion then functions as a key mechanism through which the family-induced stressor reduces OCB. We also posit that employees’ waypower and willpower can function as buffers against the emotional exhaustion that results from family incivility (Hobfoll, 2001). These two personal resources are critical components of employees' sense of hope, reflecting their propensity to devise different pathways to achieve work goals (waypower) and their agency or determination to invest necessary efforts to achieve a goal (willpower) (Luthans, Youssef, \& Avolio, 2007; Peterson \& Luthans, 2003; Rego, Machado, Leal, \& Cunha, 2009; Snyder, 2000). To the extent that employees can draw on waypower and willpower, the harmful effects of family incivility on emotional exhaustion should be mitigated, with positive consequences for their OCB.

To anchor these theoretical arguments, we rely on conservation of resources (COR) theory, which postulates that employee behavior is driven by the desire to protect or maintain existing resource bases (Hobfoll, 1989). Because exposure to resource-draining situations depletes employees’ energy reservoirs, they are motivated to avoid future resource losses by avoiding behaviors that do not seem absolutely necessary (Hobfoll, 2001; Priesemuth \& Taylor, 2016). Similarly, if employees face adversity at home, in the form of family incivility, their motivation to prevent further resource loss might steer them away from undertaking work 
activities that are not formally required by their job descriptions. Moreover, COR theory predicts an important buffering role of employees' personal resources, which can help them cope better with situations that cause stress and are resource-draining (Abbas, Raja, Darr, \& Bouckenooghe, 2014; Witt \& Carlson, 2006). Consistent with this notion that depleted energy resources due to stress-inducing situations can be compensated for by personal resources (Hobfoll, 1989, 2001), we propose that employees' waypower and willpower should mitigate the positive relationship between family incivility and emotional exhaustion. ${ }^{1}$

Accordingly, we seek to make several contributions with this study. First, previous research generally has devoted more attention to the positive factors that stimulate OCB, rather than to how resource-draining, negative factors may prevent employees' OCB. In the few studies that include negative factors, the focus is mostly on the workplace instead of the family sphere (e.g., Eatough et al., 2011; Pooja et al., 2016). In contrast, we investigate the effect of employees' exposure to rude and disrespectful behaviors in their homes, a critical stressor that resides outside the workplace and has not been explored in relation to OCB (Lim \& Tai, 2014). The results then may provide deeper insights into how employees' experience of adversity at home makes them less inclined to undertake voluntary behaviors at work, which otherwise could contribute to organizational effectiveness.

Second, we postulate that an important reason that family incivility leads to diminished OCB lies in a sense of being emotionally overextended at work (Maslach, 1993). In line with COR theory, employees' exposure to adverse family circumstances should make them reluctant

\footnotetext{
${ }^{1}$ Formally, we focus on the roles of waypower and willpower in buffering the relationship between family incivility and emotional exhaustion, not the relationship between emotional exhaustion and OCB. The positive energy associated with these two personal resources should be especially potent in preventing stress that originates in one domain (family) from spilling over to another domain (workplace), rather than having an impact on how employees respond to the outcome of this spillover effect, that is, when they already have depleted energy resources at work (Hobfoll \& Shirom, 2000; Snyder et al., 2002).
} 
to engage in voluntary work behaviors, due to their energy depletion and associated propensity to conserve resources in their work efforts (Hobfoll, 2001; McCarthy, Trougakos, \& Cheng, 2016). Previous studies show that employees' exposure to emotional exhaustion can function as a causal mechanism that connects adverse work situations, such as unfair organizational treatment (Cole, Bernerth, Walter, \& Holt, 2010) or abusive supervision (Aryee, Sun, Chen, \& Debrah, 2008), to work outcomes. However, we know of no investigation of its potential mediation of the relationship between family incivility and OCB. In this study, we propose that the negative influence of family incivility on voluntary work efforts may operate through employees' sense of being emotionally drained at work. Moreover, by focusing on the outcome of OCB, a manifestation of extra-role job performance (Williams \& Anderson, 1991), we extend the scope of previous research that has considered how psychological distress mediates the relationship between family incivility and in-role job performance (Bai et al., 2016).

Third, we investigate how employees’ waypower and willpower, two personal resources that underpin their sense of hope (Snyder, Irving, \& Anderson, 1991), may mitigate energy depletion due to family incivility, which would reduce the likelihood that they engage in OCB. Conversely, in the absence of these two personal resources, family incivility may create a particular sense of energy depletion and thus lower OCB. People who are more hopeful are better able to cope with stressful life events, such as the death of a family member (Valle, Huebner, \& Suldo, 2006) or caring for a chronically ill child (Horton \& Wallander, 2001). Organizational research similarly notes that psychological capital, of which hope is a key component, mitigates the harmful effects of dysfunctional organizational politics on employee attitudes and performance (Abbas et al., 2014). Our specific focus on waypower and willpower, the two underlying dimensions of hope, is informed by the argument that each individually may protect 
employees against the harmful effects of stressful situations (such as family incivility), yet previous studies tend to lump these two dimensions together. That is, even if extant research indicates that waypower and willpower represent two distinct dimensions of hope (e.g., Babyak, Snyder, \& Yoshinobu, 1993; Peterson \& Luthans, 2003), their individual effects are typically acknowledged post hoc (Rego et al., 2009; Rego, Sousa, Marques, \& Cunha, 2012). We instead develop separate hypotheses for how these personal resources mitigate the impact of family incivility on emotional exhaustion. In a more general sense, our focus on the moderating role of waypower and willpower extends previous research that has examined the buffering effect of other personal resources, such as core self-evaluation (Lim \& Tai, 2014) and emotional regulation (Bai et al., 2016), on the negative outcomes of family incivility.

Fourth, previous studies recognize that OCB is culturally sensitive (Blakely, Srivastava, \& Moorman, 2005; Chan \& Snape, 2013) and call for investigations of this key employee behavior in diverse settings (Felfe, Yan, \& Six, 2008; Pooja et al., 2016; Rurkkhum \& Bartlett, 2012). Compared with many Western countries, Pakistan is characterized by uncertainty avoidance, in that people tend to avoid risk and might be particularly sensitive to the experience of resource-draining, stressful family conditions (Hofstede, 2001). Therefore, for our empirical study of the beneficial role of waypower and willpower in countering the generation of emotional exhaustion in the presence of family incivility, Pakistan offers a highly relevant setting that also enables us to address calls to expand OCB studies to international levels (Chan \& Snape, 2013; Rurkkhum \& Bartlett, 2012; Vigoda-Gadot \& Grimland, 2008).

Figure 1 summarizes our conceptual framework and the constitutive hypotheses. We first propose that family incivility enhances emotional exhaustion, which diminishes OCB. Thus, emotional exhaustion is an underlying cause that reveals how this family-induced stressor steers 
employees away from positive voluntary behaviors at work. We further propose that employees' waypower and willpower function as buffers, such that the conversion of family incivility into higher emotional exhaustion, and thus lower OCB, is mitigated in their presence.

[Insert Figure 1 about here]

\section{Hypotheses}

\subsection{Mediating role of emotional exhaustion}

Employees’ experience of strain in one domain, such as the family realm, can spill over and negatively influence their functioning in another domain, such as the workplace (Ford, Heinen, \& Langkamer, 2007; Leiter \& Durup, 1996). Research on the negative interference of family with work indicates that when employees' family obligations hamper the execution of their job duties, they experience significant stress at work (Anand, Vidyarthi, Singh, \& Ryu, 2015; Cooke \& Rousseau, 1984; Zhang, Griffeth, \& Fried, 2012). Similarly, we predict a positive relationship between employees' perceptions of family incivility and their experience of emotional exhaustion during the execution of their daily job tasks. When employees are treated with disrespect at home, it may become more difficult to focus on their work goals, because of their preoccupations with their family situation and the associated tendency to respond with cognitive coping strategies that require significant energy (Lazarus \& Folkman, 1984; Lim \& Tai, 2014). Thus, their energy resource reservoirs become depleted, and they feel exhausted when they are at work. This argument is in line with the COR logic that exposure to adverse, stress-inducing environments can be so upsetting that it drains the energy resources employees have available to draw from at work (Anand et al., 2015; Hobfoll \& Shirom, 2000). In contrast, when employees perceive little family incivility, their organizational functioning is not compromised, so they are less likely to feel emotionally drained at work. 
In addition, employees’ exposure to family incivility may deplete their energy resources indirectly, in that exposure to rude or demeaning comments from family members may create doubt about whether their work efforts are appreciated; that is, family incivility may signal disrespect for their job-based contributions to the family’s well-being (Lim \& Lee, 2011) Similarly, if they suffer incivility at home, employees may experience reduced self-esteem (Bai et al., 2016), resentment, or dissatisfaction about their life situation (Ford et al., 2007). Such feelings fuel more emotional exhaustion at work, reflecting concerns about the meaningfulness of their work efforts (Hobfoll, 2001; Leiter \& Durup, 1996). Conversely, if treated with respect at home, employees should develop more positive views of their work efforts, because they feel appreciated by their family for these efforts (Lim \& Lee, 2011). In short, to the extent that employees enjoy a respectful family environment, they possess more positive feelings about their work situation and are less likely to be overwhelmed by their daily job obligations.

Hypothesis 1: There is a positive relationship between employees' perceptions of family incivility and their emotional exhaustion at work.

In turn, employees' emotional exhaustion at work should diminish their OCB. When employees feel emotionally overextended, they become preoccupied with their organizational functioning and ability to meet formal job obligations (McCarthy et al., 2016). According to COR theory, these feelings should diminish OCB, because the associated energy depletion motivates employees to conserve resources to avoid further resource losses (Hobfoll \& Shirom, 2000). The sense of being emotionally spent during the execution of job tasks also tends to steer employees toward negative activities, such as psychological withdrawal (Chi \& Liang, 2013), absenteeism (Bronkhorst \& Vermeeren, 2016), or intentions to leave the organization (Bernerth, Walker, Walter, \& Hirschfeld, 2011). The energy-draining effect of emotional exhaustion thus 
leaves employees more passive or indifferent with regard to the possibility of voluntarily helping the organization meet its objectives.

Employees who feel emotionally drained by their work also tend to identify less strongly with their organization (Mulki, Jaramillo, \& Locander, 2006; Walsh, Dahling, Schaarschmidt, \& Brach, 2016), which may fuel their reluctance to engage in discretionary activities that otherwise could benefit their organization. Conversely, employees who do not suffer from emotional exhaustion likely are more motivated to go out of their way to undertake discretionary behaviors from which their organization can benefit (Aryee et al., 2008). That is, employees who do not suffer from depleted energy resource bases likely feel more excited about the possibility of helping their organization achieve its goals (Hobfoll, 2001), such that the likelihood that they are willing to engage in OCB increases. We hypothesize:

Hypothesis 2: Employees' emotional exhaustion at work relates negatively to their OCB. Combining these arguments, we anticipate a mediating role of emotional exhaustion, such that employees' exposure to family incivility reduces their OCB because of their feelings of being emotionally drained at work. Employees who are treated disrespectfully by their family members are more likely to avoid such positive work behaviors, because they are motivated to conserve their energy and reduce efforts devoted to activities that are not formally required (Hobfoll, 2001; Quinn et al., 2012). Previous research reveals a mediating role of emotional exhaustion in adverse work situations, such as organizational climates that provide insufficient psychological safety (Bronkhorst \& Vermeeren, 2016), injustice (Cole et al., 2010), or dysfunctional leadership (Aryee et al., 2008; Chi \& Liang, 2013). We similarly propose that emotional exhaustion mediates the relationship between family incivility and OCB, so feelings 
of being overextended emotionally provide the conduits through which an unfavorable family situation reduces OCB.

Hypothesis 3: Employees' emotional exhaustion at work mediates the relationship between their perceptions of family incivility and their OCB.

\subsection{Moderating role of waypower}

According to COR theory, the harmful effect of a stressful situation should be lower when people can draw from personal resources that compensate for the anticipated resource loss (Hobfoll, 2001; Witt \& Carlson, 2006). Waypower, or the propensity to devise alternative pathways to achieve desirable work goals (Snyder, 2000), is one such personal resource that should enable employees to find effective solutions to the challenge of adverse family dynamics. Employees who score high on waypower likely explore different strategies that may enable them to meet their job obligations, even while they suffer from a stressful family life (Cheavens, Feldman, Snyder, \& Woodward, 2006; Snyder, Rand, \& Sigmon, 2002). For example, they may become more efficient in meeting their performance targets by identifying different methods to complete their work tasks, so they become better able to prevent family-induced stress due to incivility from undermining their work duties (Hobfoll, 2001; Irving, Snyder \& Crowson, 1998). In a similar vein, previous research suggests that employees' waypower increases their creativity with regard to finding adequate solutions to challenging situations (Rego et al., 2009).

The buffering role of waypower also might result from employees' tendency to rely on a wider set of organizational peers in their efforts to achieve work goals (Snyder, 2000). Because employees high on waypower may spend more time building diverse social relationships with colleagues, they can obtain more input about how to cope with challenges that they face at home (Ford et al., 2007), which should increase their confidence that they can protect themselves

against such challenges (Lim \& Tai, 2014) and thereby mitigate their emotional exhaustion. The 
sense of mutual support associated with reaching out to organizational peers also may generate perceptions of a common fate or "being in the same boat" (Cohen \& Wills, 1985; Ryan \& Deci, 2000), which should reduce the spillover of family incivility onto emotional strain at work (Leiter \& Durup, 1996). When their waypower is low though, employees are less likely to receive varied feedback from their colleagues in terms of how to protect against such spillovers (Snyder, 2000), and their feelings of being emotionally overextended at work may grow (Ford et al., 2007; Hobfoll, 1989). In this case, the likelihood that family incivility escalates into feelings of being emotionally overextended becomes particularly strong.

Hypothesis 4: The positive relationship between employees’ perceptions of family incivility and their emotional exhaustion at work is moderated by their waypower, such that this positive relationship is weaker at higher levels of waypower.

\subsection{Moderating role of willpower}

We also expect that the positive relationship between family incivility and emotional exhaustion at work is buffered by employees' willpower, defined as their drive or motivation to achieve desirable work goals (Snyder, 2000). Willpower implies the presence of goal-directed thinking or a propensity to allocate sustained personal energy toward goal attainment (Peterson \& Luthans, 2003; Snyder et al., 1991). This personal resource should be useful when employees are distressed by their exposure to discourteous treatment by family members, because willpower enhances their perseverance in finding solutions to challenging situations (Rego et al., 2009; Snyder, Lapointe, Crowson, \& Early, 1998), so it should reduce the likelihood that family incivility escalates into feelings of being overextended (Hobfoll, 2001). For example, employees who score high on willpower and face uncivil behaviors by family members likely invest significant energy in trying to undo the negative work consequences of this home-based challenge, such as by applying their personal skill sets to the successful execution of their job tasks (Snyder, 2000). Employees with low willpower instead might just sit back and ruminate on 
the unpleasantness of their family situation, which would spur stronger feelings of being emotionally overwhelmed at work (Lim \& Tai, 2014).

Moreover, because strong willpower leads employees to do whatever it takes to achieve desired work goals, their efforts produce personal satisfaction, in that these employees enjoy the challenge of finding effective solutions to adverse situations and learning from these efforts (Peterson \& Luthans, 2003; Snyder, 2000). Employees who score high on willpower regard problem situations as challenges or learning opportunities, instead of threats (Rego et al., 2009), so they should exhibit a strong intrinsic motivation to leverage their personal knowledge to cope with their challenging home situation (Ryan \& Deci, 2000). Greater willpower therefore should reduce the potency with which family incivility enhances emotional exhaustion, due to the desirability of taking on and settling this challenging personal situation (Lim \& Tai, 2014). Conversely, employees with less willpower experience less joy from their attempts to prevent the negative interference of family-induced hardship with their work, which increases the likelihood that they feel emotionally overextended (Hobfoll, 2001).

Hypothesis 5: The positive relationship between employees’ perceptions of family incivility and their emotional exhaustion at work is moderated by their willpower, such that this positive relationship is weaker at higher levels of willpower.

Combining Hypotheses 3-5, we also predict a moderated mediation effect (Preacher, Rucker, \& Hayes, 2007), such that waypower and willpower serve as two contingent, buffering factors for the indirect effects of family incivility on OCB, through emotional exhaustion. Such moderated mediation implies that at high levels of waypower and willpower, the causal role of emotional exhaustion, connecting the family-based stressor to reduced OCB, should be mitigated. Thus, in line with COR theory (Anand et al., 2015; Hobfoll, 2001), we predict that the two personal resources diminish the chances that energy depletion in response to a resourcedraining condition, such as family incivility, leads to a reluctance to engage in OCB. 
Alternatively, employees who cannot draw from these personal resources are more sensitive to the hardships caused by uncivil behaviors at home, so they are more likely to turn away from positive voluntary behaviors, because they feel emotionally overextended.

Hypothesis 6: The indirect negative relationship between employees' perceptions of family incivility and OCB through their emotional exhaustion at work is moderated by their waypower, such that this indirect relationship is weaker at higher levels of waypower.

Hypothesis 7: The indirect negative relationship between employees' perceptions of family incivility and OCB through their emotional exhaustion at work is moderated by their willpower, such that this indirect relationship is weaker at higher levels of willpower.

\section{Research methods}

\subsection{Data collection}

The data were collected from eight Pakistani organizations, operating in a variety of sectors (e.g., food, education, health, telecom, textiles). These organizations were approached through the professional and personal contacts of two of the authors. The data were collected through personal visits by these authors to the organizational sites, during which the surveys were distributed to the respondents individually. Participation was voluntary, and participants were guaranteed complete confidentiality and assured that only aggregate results would be included in any reports. The participants were asked to deposit their responses in a secure dropbox, placed in their organization for the specific purpose of this study. The researchers were the only persons with access to the dropbox. There were no monetary incentives or any other gifts given to participants; however, we communicated that the findings of this research effort would benefit the overall effectiveness of their organization.

Three paper-and-pencil surveys were conducted, and two of them were distributed to employees, separated by a three-week time lag. The third survey took place another three weeks 
later, after the second employee survey. This survey involved randomly selected peers who worked in the same department as the original respondents, such that they should have sufficient knowledge about their colleagues’ work behaviors; they assessed those colleagues’ OCB. Each peer rated no more than two employees, to prevent data nesting. The reliance on peer-rated measures of OCB helps avoid concerns of common method bias and is consistent with previous studies (e.g., Naseer et al., 2016; Raja \& Johns, 2010). Moreover, a recent meta-analysis indicated very small differences in OCB ratings across different sources (Carpenter, Berry, \& Houston, 2014). The first survey asked the employees about family incivility, waypower, and willpower; the second queried them about their emotional exhaustion; and the third asked peers to rate colleagues' OCB.

The survey questions were originally prepared in English and then translated into Urdu by a bilingual translator. To ensure the quality of the translation and avoid cultural bias, these translated versions were back-translated into English by another bilingual translator (Brislin, Lonner, \& Thorndike, 1973). Some minor changes produced the final versions of the administered surveys in Urdu. All three surveys were preceded by cover letters that assured participants that there were no right or wrong answers and that all their answers would remain completely confidential and accessible only to the research team. The letters also asked the respondents to answer the questions as honestly as possible. Thus, concerns about social desirability or acquiescence bias should be minimal (Spector, 2006).

Of the 330 surveys distributed in the first round, we received 270 completed responses, for a response rate of $81 \%$. These respondents were contacted again after three weeks, which generated 220 completed responses. Finally, the peers of these 220 respondents were contacted to rate their colleagues' OCB, which led to 210 completed response sets (reflecting an overall 
response rate of 63\%) for the analyses. The employee sample had the following characteristics: 34\% women, $47 \%$ married, $43 \%$ belonged to a joined family (e.g., grandparents or adult siblings living in the same home) instead of a nuclear family, $67 \%$ had a university degree, and the average tenure at their organizations was 4.5 years.

\subsection{Measures}

The measures of all focal constructs contained items from previous research.

Organizational citizenship behavior. We assessed peer-rated OCB with a seven-point Likert scale that contains seven items, as developed by Williams and Anderson (1991) and applied in several studies of positive work behaviors (e.g., Donia, Raja, Panaccio, \& Wang, 2016; Karriker \& Williams, 2009; Naseer et al., 2016). Two sample items are "This employee has work attendance above the norm" and "This employee adheres to informal rules devised to maintain order” (Cronbach’s alpha = .73).

Emotional exhaustion. We measured the level of emotional exhaustion that employees experience at work with a five-point Likert scale that included nine items. This scale was developed by Maslach and Jackson (1981) and has been used in previous studies on employee stress (e.g., Sassi, El Akremi, \& Vandenberghe, 2015; Wright \& Cropanzano, 1998). The respondents indicated, for example, whether "I feel emotionally drained from my work" and "I feel used up at the end of the workday” (Cronbach’s alpha $=.93$ ).

Family incivility. To assess employees’ perceptions of incivility in their homes, we relied on seven items, measured on a five-point Likert scale, as developed by Lim and Tai (2014) and subsequently applied by Bai and colleagues (2016). Two example items were "My family members put me down or are condescending to me" and "My family members pay little attention 
interest in my opinion.” Similar to Lim and Tai (2014), we emphasized in the survey that these statements pertained to any family members, instead of a specific one (Cronbach's alpha $=.83$ ).

Waypower and willpower. We assessed the two personal resources of waypower and willpower with three items each, using six-point Likert scales from previous studies (Luthans, Avolio, Avey, \& Norman, 2007; Rego, Marques, Leal, Sousa, \& Cunha, 2010; Rego et al., 2012). A sample item for waypower is, "I can think of many ways to reach my current work goals,” and one for willpower is, “At the present time, I am energetically pursuing my work goals.” The reliabilities of these two personal resources were acceptable (waypower .80, willpower .76). To assess whether waypower and willpower represent two distinct personal resources, we undertook an exploratory factor analysis (Table 1). The measurement items loaded strongly on their respective factors (i.e., . 70 or higher), and the cross-loadings were low (i.e., less than .40). Moreover, in a confirmatory factor analysis, we compared the fit of a one-factor model in which all six items load on a single factor $\left(\chi^{2}(9)=24.90\right)$, with that of a two-factor model in which the items load on their respective factor $\left(\chi^{2}(8)=15.30\right)$. The fit of latter model was significantly better than that of the former $\left(\Delta \chi^{2}(1)=9.60, p<.01\right)$, signaling that waypower and willpower represent two distinct dimensions of hope, similar to previous findings (Babyak et al., 1993; Rego et al., 2009).

\section{[Insert Table 1 about here]}

Control variables. The statistical models controlled for five additional variables: gender ( 1 = female), marital status $(1$ = married), family type (i.e., nuclear or joint family, with the former as the base category), education ( 1 = secondary, 2 = bachelor, 3 = masters), and organizational tenure (in years).

\section{Results}


Table 2 contains the correlations and descriptive statistics for the study variables; the regression results are in Table 3. Models 1-3 predicted perceptions of emotional exhaustion, and Models 4-7 predicted OCB. For each model, the variance inflation factor values were less than 10, so multicollinearity was not a concern (Aiken \& West, 1991).

[Insert Tables 2 and 3 about here]

In Hypothesis 1 we predicted that employees who perceive they are treated with rudeness and disrespect by family members are more likely to feel emotionally drained at work. In support of this hypothesis, we find a positive relationship between family incivility and emotional exhaustion in Model $2(\beta=.61, p<.001)$. The feeling of being emotionally overextended at work also steers employees away from undertaking voluntary work efforts, as indicated by the negative relationship between emotional exhaustion and OCB in Model 7 ( $\beta=-.14, p<.01)$.

To assess the presence of mediation by perceptions of emotional exhaustion, we apply the well-established bootstrapping method by Preacher and colleagues (2007), which provides confidence intervals for indirect effects, thereby avoiding potential statistical power problems that might be caused by asymmetric and other non-normal sampling distributions (MacKinnon, Lockwood, \& Williams, 2004). The confidence interval for the indirect effect of family incivility on OCB through emotional exhaustion does not include 0 [-.27, -.07], in support of the presence of mediation.

To test the moderating effects of waypower and willpower (Hypotheses 4 and 5), we calculate interaction terms: family incivility $\times$ waypower and family incivility $\times$ willpower (Models 3 and 4, respectively). Including multiple interaction terms in separate models is a wellestablished practice, because their simultaneous presence in a single model might mask true moderating effects (e.g., Covin, Green, \& Slevin, 2006; De Clercq, Bouckenooghe, Raja, \& 
Matsyborska, 2014). Both interaction terms are significant $(\beta=-.18, p<.05 ; \beta=-.20, p<.01$, respectively). We also plot the effect of family incivility on emotional exhaustion at high and low levels of waypower in Figure 2 and high and low levels of willpower in Figure 3. The graphs indicate that the spillover of family incivility into emotional exhaustion at work is weaker to the extent that employees can draw from their personal resources of waypower and willpower.

[Insert Figures 2 and 3 about here]

Finally, the test for the moderated mediation effect in Hypotheses 6 and 7 relied on Preacher et al.’s (2007) SPSS “modmed” macro and its bootstrapping function. Establishing moderated mediation requires determining whether the indirect effect of family incivility on OCB, through emotional exhaustion, differs at various levels of the moderators. ${ }^{2}$ Similar to the bootstrapping procedure to test for mediation, the procedure in this case generates confidence intervals rather than point estimates (MacKinnon et al., 2004). The bootstrap 95\% confidence interval for the conditional effect of family incivility on OCB did not contain 0 when waypower and willpower were low ([-.45, -.12] and [-.46, -.14], respectively), but it contained 0 when the two moderators were high ([-.19, .01] and [-.19, .02], respectively). Moreover, the confidence intervals for the index of moderated mediation (Hayes, 2015) did not include 0 ([.01; .10] and $[.01, .09]$, respectively). Overall, these results suggest that waypower and willpower serve as buffers against the negative indirect effect of family incivility on OCB through emotional exhaustion, in support of Hypotheses 6 and 7.

\section{Discussion}

\footnotetext{
${ }^{2}$ Consistent with the hypothesized framework, and the argument that the positive energy generated by hope should buffer the negative effect of the original source of the stress (family incivility) rather than the effect of its secondhand manifestation (emotional exhaustion at work; Hobfoll \& Shirom, 2000), waypower and willpower should moderate the relationships between family incivility and emotional exhaustion, but not the relationship between emotional exhaustion and OCB. A post hoc analysis, in which these personal resources did not moderate this latter relationship, confirmed this argument.
} 
With this study, we contribute to extant research by examining the effect of employees' perceptions of family incivility on their OCB, as well as factors that inform this process. Despite the acknowledged need to understand the role of family incivility in inhibiting positive performance outcomes (Lim \& Tai, 2014) or generating deviant behaviors (Bai et al., 2016), no research has investigated why employees' family incivility might undermine their OCB, or the circumstances in which this negative effect might be less likely. To address these gaps, we draw from COR theory (Hobfoll, 1989, 2001) and propose that the reduction in voluntary positive work efforts in response to family incivility occurs because employees become emotionally exhausted at work (Maslach, 1993), but the personal resources of waypower and willpower can mitigate this process (Rego et al., 2009; Snyder, 2000). Our results provide empirical support for these theoretical predictions.

The positive relationship between family incivility and emotional exhaustion indicates that exposure to uncivil behaviors at home—-such as receiving demeaning or degrading remarks, or being ignored or excluded from family activities (Lim \& Tai, 2014)—has implications for how employees feel about their job situation. In the presence of strong family incivility, employees' energy resources at work become drained, and they worry about their organizational functioning and ability to fulfill their job duties (Lim \& Tai, 2014; Leiter \& Durup, 1996). When they are victims of family incivility, employees have less energy to meet their work goals, and the resulting hardship makes them feel emotionally overextended (Hobfoll, 1989; Quinn et al., 2012). If employees instead are treated with respect by their family members, they are less likely to feel overwhelmed by their job obligations. Moreover, emotional exhaustion represents a key mechanism through which family incivility translates into lower OCB. Going beyond activities required by formal job responsibilities demands significant energy (Podsakoff et al., 2009), and 
employees who confront stressful situations at home may not possess sufficient energy to undertake such activities (Hobfoll, 2001; Quinn et al., 2012). Thus, the contribution of family incivility to employees' reluctance to engage in OCB becomes manifest as feelings of being emotionally overwhelmed at work (Maslach \& Jackson, 1981).

The results also reveal that the positive effect of family incivility on emotional exhaustion is influenced by how hopeful employees are, which operates through two distinct dimensions: waypower and willpower (Babyak et al., 1993; Snyder, 2000). Emotional exhaustion is less likely to emerge from family incivility to the extent that employees tend to search for different pathways to achieve desirable work goals and are motivated to do whatever it takes to achieve these work goals when following a particular pathway. The buffering roles of waypower and willpower are consistent with COR theory, which emphasizes that the relative importance of resource-draining situations in explaining energy depletion diminishes in the presence of relevant personal resources (Hobfoll, 2001; Witt \& Carlson, 2006). Thus, the stress associated with family incivility is less likely to spill over to the workplace in the form of emotional exhaustion if employees can rely on personal resources that inform their ability and motivation to meet their work goals.

First, strong waypower increases employees’ propensity to explore different means to meet work goals, either independently or through enhanced interactions with peers, which serves as a protection against the stress induced by exposure to uncivil behaviors at home (Cheavens et al., 2006; Snyder et al., 2002). In addition, the ability to devise effective pathways to reach work goals in the presence of adverse family conditions may generate positive feelings of fulfillment in employees (Ryan \& Deci, 2000), such that it becomes less likely that they suffer from emotional exhaustion at work. Second, when they can draw from their strong willpower, 
employees are more persistent in finding effective solutions to the challenge of a negative interference of uncivil family treatment with work duties, which subdues the sense of being emotionally overextended during daily job tasks (Snyder et al., 1998). The personal satisfaction that comes with a strong determination to meet work goals also may alleviate the likelihood that family incivility translates into enhanced emotional exhaustion at work. Notably, our finding that the buffering role of willpower is somewhat stronger than that of waypower (Models 3 and 4) is consistent with previous studies that find that willpower has more predictive power in explaining how employees find creative solutions to challenging situations (Rego et al., 2009, 2012).

When considering the buffering roles of the two personal resources in combination with the negative impact of emotional exhaustion on OCB, the results also reveal that the harmful indirect effect of family incivility on OCB, through enhanced emotional exhaustion, is less salient when those personal resources are abundant. To the extent that employees possess high levels of waypower and willpower, they are better able to fulfill their job duties (Peterson \& Luthans, 2003; Snyder et al., 2000), even in the presence of adverse treatments at home, and as a result, they have sufficient residual energy to engage in voluntary work efforts that contribute to their organization’s success (Hobfoll, 2001; Podsakoff et al., 2009). Conversely, when employees have less waypower and willpower, the experience of being overwhelmed by work due to family incivility escalates, and the indirect relationship between family incivility and OCB grows stronger. Hardships due to adverse family relationships thus translate more readily into lower OCB through emotional exhaustion, to the extent that employees cannot rely on the buffering role of these two personal resources.

Overall, this more complete understanding of the consequences of family incivility for the voluntary activities that employees undertake in the workplace extends extant scholarship by 
(1) pinpointing the role of a hitherto unexplored external stressor (family incivility) in relation to OCB, (2) revealing how negative feelings of being emotionally overextended (i.e., emotional exhaustion) serve as key mechanisms that connect this resource-draining external factor with lower OCB, and (3) showing how employees' waypower and willpower mitigate the translation of family incivility into lower OCB through emotional exhaustion.

\subsection{Limitations and future research}

This study has some shortcomings, which suggest avenues for further research. Some caution is needed in terms of the causality of the relationships. Employees who engage in OCB may develop positive feelings of personal fulfillment (Podsakoff et al., 2009), such that they might suffer less from emotional exhaustion during the execution of their job tasks. Such emotional exhaustion at work in turn might make employees more vulnerable to adverse treatment by family members. Even though the direction of our hypotheses was grounded in extant theory, and we imposed time gaps between our assessments of family incivility, emotional exhaustion, and OCB, further research with longer, longitudinal designs could investigate the causal processes that link these three factors, as well as the potential boundary conditions that influence the process.

In a similar vein, it would be interesting to assess, in a single study, the relative strength of our focal mediator (emotional exhaustion) compared with that of other causal mechanisms examined in previous studies on the outcomes of family incivility—such as psychological distress (Lim \& Tai, 2014) or self-esteem (Bai et al., 2016)—as well as to compare the salience of the mediating effect of emotional exhaustion for predicting in-role performance (Lim \& Tai, 2014) and negative work behaviors (Bai et al., 2016). Also, we did not directly measure the theorized focal mechanism that links family incivility and emotional exhaustion, namely, the loss 
of energy resources. Although this mechanism is grounded in the well-established COR theory (Hobfoll, 1989, 2001), it might be helpful to assess this mechanism directly.

Furthermore, we focused on waypower and willpower as contingency factors that influence the mediated relationship between family incivility and OCB. Continued research might investigate how other personal factors, such as employees' creative self-efficacy (Tierney \& Farmer, 2002) or emotional stability (Johnson, Rogers, Stewart, David, \& Witt, 2017), might protect them from the energy drainage that results from family incivility. Comparative studies also could address the prominence of this study’s focal moderators (waypower and willpower) with that of other factors that previous research has identified as buffers of the negative effects of family incivility for alternative outcomes, such as emotional regulation (Bai et al., 2016) and core self-evaluation (Lim \& Tai, 2014). Such research also could consider organizational resources, such as whether the organization adopts adequate stress management counseling (Ormond, Keown-Gerrard, \& Kline, 2003) or implements supportive work-life balance measures (ten Brummelhuis \& van der Lippe, 2010), and their influences.

Finally, our results reflect data from organizations based in one country, Pakistan. Although our conceptual arguments are general and not country-specific, cultural issues could influence our conceptual framework. For example, in this high uncertainty avoidance country, people likely are sensitive to personal circumstances that create uncertainty and stress in their lives (Hofstede, 2001), so the potency with which waypower and willpower buffer the negative impact of family incivility on OCB through reduced emotional exhaustion may be stronger than it would be in less uncertainty-averse countries. Cross-country comparisons could provide insights into the relative importance of employees’ personal resources for preventing the harmful spillover of family-related adversity into workplace settings. 


\subsection{Practical implications}

For organizational decision makers, this study also offers practical insights. A significant source of workplace stress for employees can come from outside the workplace (Lim \& Tai, 2014), but employees are unlikely to be eager to report such stresses, especially if they believe these issues belong to the personal sphere (Bai et al., 2016). Yet the negative feelings that stem from family incivility can be detrimental and lead to a sense of being overwhelmed by work, which spurs the belief that undertaking voluntary work efforts is neither realistic nor desired. Organizations need to acknowledge employees' concerns about family situations when evaluating their organizational functioning; they should encourage employees to speak openly about problems at home, if they so choose. For example, during performance evaluation sessions, managers might prompt employees to explain how their ability to meet preset performance standards could be compromised by difficult family circumstances. In addition, organizations can benefit from creating clarity about work goals and how to reach them (e.g., time, budget). With this clarity, it may be less likely that employees' ability to meet employer expectations will be compromised by the emergence of emotional exhaustion due to external conditions.

Some stress associated with family issues likely is inevitable though, so organizations also need to find ways to reduce the likelihood that the hardship of family incivility translates into higher emotional exhaustion and lower OCB. When employees perceive that family members do not treat them with respect, the associated stress does not convert as readily into emotional strain if they can use their personal resources of waypower and willpower. The enhanced energy and positive emotions that come with these resources help employees cope more effectively with frustration (Snyder, 2000). To the extent that employees experiment with 
different paths to deal with the daily challenges of their job and are determined to meet their work goals, they might be less concerned about their ability to perform their job tasks effectively and less likely to feel overwhelmed by their work if they face adverse situations at home, so the likelihood that they subsequently stay away from OCB diminishes.

Increased levels of waypower and willpower thus reflect important means for organizations to maintain voluntary work efforts among their employee bases, particularly when family incivility cannot be avoided completely. Organizations should account for such personal resources in hiring processes; certain employees, due to their personal characteristics, will be better equipped to immunize their organizational performance against the negative impact of uncivil treatments at home. Moreover, waypower and willpower can be developed (Luthans, 2002; Peterson \& Luthans, 2003); clinical psychology research even emphasizes the usefulness of "hope therapy" to help people overcome challenging life situations (Lopez, Snyder, \& Teramoto-Pedrotti, 2003). Similarly, organizations could design training interventions to support employees' efforts to develop waypower and willpower, perhaps by focusing on good work goal designs, generating pathways, and encouraging persistence to achieve goals (Luthans, Avey, Avolio, Norman, \& Combs, 2006; Snyder, 2000).

Finally, to avoid the negative outcomes of emotional exhaustion at work and the associated reluctance to engage in OCB, organizations could use a targeted approach and implement measures that stimulate employees who score low on waypower and willpower to talk about the challenges they experience at home, as well as how these challenges might affect their ability to meet performance targets. Ultimately, these efforts can prevent employees from becoming completely drained at work because of their precarious family situation, leaving them 
with sufficient energy to engage in activities that are not formally required by their job descriptions.

\subsection{Conclusion}

We have contributed to OCB research by examining the effect of family-induced stress, in the form of exposure to uncivil behaviors by family members, on employees' propensity to engage in OCB. The emotional exhaustion that employees experience at work functions as a causal mechanism that explains why family incivility diminishes positive voluntary work efforts. We also reveal that this challenge is contingent on two relevant personal resources that employees might draw from, in terms of how they approach their work goals. The extent to which employees (1) consider different pathways to meet desirable work goals and (2) are determined to do whatever it takes to be successful in these endeavors helps them cope better with stress due to family incivility. Thus, their waypower and willpower serve as effective buffers against the energy drainage that arises due to family incivility, which in turn thwarts a reluctance to undertake OCB. We hope this study functions as a catalyst for more investigations of how a reluctance to engage in positive work behaviors might be avoided in the presence of resource-depleting conditions, whether they reside inside or outside the workplace. 


\section{References}

Abbas, M., Raja, U., Darr, W., \& Bouckenooghe, D. (2014). Combined effects of perceived politics and psychological capital on job satisfaction, turnover intentions, and performance. Journal of Management, 40, 1813-1830.

Aiken, L. S. \& West, S. G. (1991). Multiple regression: Testing and interpreting interactions. Newbury Park, CA: Sage.

Amstad, F.T., Meier, L.L., Fasel, U., Elfering, A., \& Semmer, N.K. (2011). A meta-analysis of work-family conflict and various outcomes with a special emphasis on cross-domain versus matching-domain relations. Journal of Occupational Health Psychology, 16, 151-169.

Anand, S., Vidyarthi, P., Singh, S., \& Ryu, S. (2015). Family interference and employee dissatisfaction: Do agreeable employees better cope with stress? Human Relations, 68, 691708.

Aryee, S., Sun, L.Y., Chen, Z.X., \& Debrah, Y.A. (2008). Abusive supervision and contextual performance: The mediating role of emotional exhaustion and the moderating role of work unit structure. Management and Organization Review, 4, 393-411.

Babyak, M.A., Snyder, C.F., \& Yoshinobu, L. (1993). Psychometric properties of the Hope scale: A confirmatory factor analysis. Journal of Research in Personality, 27, 154-169.

Bai, Q., Lin, W., \& Wang, L. (2016). Family incivility and counterproductive work behavior: A moderated mediation model of self-esteem and emotional regulation. Journal of Vocational Behavior, 94, 11-19.

Bernerth, J.B., Walker, H.J., Walter, F., \& Hirschfeld, R.R. (2011). A study of workplace justice differences during times of change: It's not all about me. Journal of Applied Behavioral Science, 47, 336-359.

Blakely, G.L., Srivastava, A., \& Moorman, R.H. (2005). The effects of nationality, work role centrality, and work locus of control on role definition of OCB. Journal of Leadership and Organizational Studies, 12, 103-117.

Bowling, N.A., Wang, Q., \& Li, H.Y. (2012). The moderating effect of core self-evaluations on the relationships between job attitudes and organisational citizenship behavior. Applied Psychology: An International Review, 61, 97-113.

Brislin, R. W., Lonner, W., \& Thorndike, R.M. (1973). Cross-cultural research methods. New York: John Wiley \& Sons.

Bronkhorst, B., \& Vermeeren, B. (2016). Safety climate, worker health and organizational health performance: Testing a physical, psychosocial and combined pathway. International Journal of Workplace Health Management, 9, 270-289.

Carpenter, N.C., Berry, C.M., \& Houston, L. (2014). A meta-analytic comparison of self reported and other-reported organizational citizenship behavior. Journal of Organizational Behavior, 35, 547-574.

Chan, A.W., \& Snape, E. Are cultural values associated with organizational and union commitment and citizenship behavior? A study of Chinese manufacturing workers. Asia Pacific Journal of Management, 30, 169-190.

Cheavens, J., Feldman, D., Snyder, C. R., \& Woodward, J. (2006). Hope in cognitive psychotherapies: On working with client strengths. Journal of Cognitive Psychotherapy: An International Quarterly, 20, 135-145. 
Chi, S.-C. S., \& Liang, S.-G. (2013). When do subordinates' emotion-regulation strategies matter? Abusive supervision, subordinates' emotional exhaustion, and work withdrawal. Leadership Quarterly, 24, 125-137.

Cohen, S. \& Wills, T. A. (1985). Stress, social support, and the buffering hypothesis. Psychological Bulletin, 98, 310-357.

Cohen-Charash, Y. \& Spector, P.E. (2001). The role of justice in organizations: A meta-analysis. Organizational Behavior and Human Decision Processes, 86, 278-321.

Cole, M.S., Bernerth, J.B., Walter, F., \& Holt, D.T. (2010). Organizational justice and individuals' withdrawal: Unlocking the influence of emotional exhaustion. Journal of Management Studies, 47, 367-390.

Cooke, R.A., \& Rousseau, D.M. (1984). Stress and strain from family roles and work-role expectations. Journal of Applied Psychology, 69, 252-260

Covin, J.G., Green, K.M., \& Slevin, D.P. (2006). Strategic process effects on the entrepreneurial orientation-sales growth rate relationship. Entrepreneurship Theory and Practice, 30, 57-81.

Deckop, J.R., Cirka, C.C., \& Andersson, L.M. (2003). Doing unto others: The reciprocity of helping behavior in organizations. Journal of Business Ethics, 47(2), 101-113.

De Clercq, D., Bouckenooghe, D., Raja, U., \& Matsyborska, G. (2014). Unpacking the goal congruence-organizational deviance relationship: The roles of work engagement and emotional intelligence. Journal of Business Ethics, 124, 695-711.

Donia, M.B.L., Raja, U., Panaccio, A., \& Wang, Z. (2016). Servant leadership and employee outcomes: The moderating role of subordinates' motives. European Journal of Work and Organizational Psychology, 25, 722-734.

Eatough, E. M., Chang, C. H., Miloslavic, S. A., \& Johnson, R. E. (2011). Relationships of role stressors with organizational citizenship behavior: A meta-analysis. Journal of Applied Psychology, 96, 619-632.

Felfe, J., Yan, W., \& Six, B. (2008). The impact of individual collectivism on commitment and its influence on organizational citizenship behavior and turnover in three countries. International Journal of Cross Cultural Management, 8, 211-237.

Ford, M.T., Heinen, B. A., \& Langkamer, K.L. (2007). Work and family satisfaction and conflict: A meta-analysis of cross-domain relations. Journal of Applied Psychology, 92, 5780.

Hayes, A.F. (2015). An index and test of linear moderated mediation. Multivariate Behavioral Research, 50, 1-22.

Hobfoll, S.E. (1989). Conservation of resources. A new attempt at conceptualizing stress. American Psychologist, 44, 513-524.

Hobfoll, S.E. (2001). The influence of culture, community, and the nested-self in the stress process: Advancing conservation of resource theory. Applied Psychology: An International Review, 50, 337-369.

Hobfoll, S.E., \& Shirom, A. (2000). Conservation of resources theory: Applications to stress and management in the workplace. In R.T. Golembiewski (Ed.), Handbook of organization behavior ( ${ }^{\text {nd }}$ ed., pp. 57-81). New York: Dekker.

Hofstede, G. (2001). Culture's consequences: Comparing values, behaviors, institutions and organizations across nations, 2d ed. Thousand Oaks, CA: Sage.

Horton, T.V., \& Wallander, J.L. (2001). Hope and social support as resilience factors against psychological distress of mothers who care for children with chronic physical conditions. Rehabilitation Psychology, 46, 382-399. 
Irving, L.M., Snyder, C.R., \& Crowson Jr., J.J. (1998). Hope and the negotiation of cancer facts by college women. Journal of Personality, 66, 195-214.

Johnson, L.U., Rogers, A., Stewart, R., David, E.M., \& Witt, L.A. (2017). Effects of politics, emotional stability, and LMX on job dedication. Journal of Leadership \& Organizational Studies, 24, 121-130.

Karriker, J.H., \& Williams, M.L. (2009). Organizational justice and organizational citizenship behavior. Journal of Management, 35, 112-135.

Lazarus, R. S. \& Folkman, S. (1984). Stress, appraisal, and coping. New York: Springer.

Leiter, M.P., \& Durup, M.J. (1996). Work, home, and in-between: A longitudinal study of spillover. Journal of Applied Behavioral Science, 32, $29-47$.

Lievens, F., De Corte, W., \& Schollaert, E. (2008). A closer look at the frame-of-reference effect in personality scale scores and validity. Journal of Applied Psychology, 93, 268-279.

Lim, S., \& Lee, A. (2011). Work and nonwork outcomes of workplace incivility: Does family support help? Journal of Occupational Health Psychology, 16, 95-111.

Lim, S., \& Tai, K. 2014. Family incivility and job performance: A moderated mediation model of psychological distress and core self-evaluation. Journal of Applied Psychology, 99, 351359.

Lopez, S.J., Snyder, C.R., \& Teramoto-Pedrotti, J. (2003). Hope: Many definitions, many measures. In S.J. Lopez \& C.R. Snyder (Eds.), Positive Psychological Assessment: A Handbook of Models and Measures (pp. 91-107). Washington, DC: American Psychological Association.

López-Domínguez, M., Enache, M., Sallan, J.M., \& Simo, P. (2013). Transformational leadership as an antecedent of change-oriented organizational citizenship behavior. Journal of Business Research, 66, 2147-2152.

Luthans, F. (2002). The need for and meaning of positive organizational behavior. Journal of Organizational Behavior, 3, 695-706.

Luthans, F., Avolio, B.J., Avey, J.B., \& Norman, S.M. (2007). Positive psychological capital: Measurement and relationship with performance and satisfaction. Personnel Psychology, 60, 541-572.

Luthans, F., Avey, J.B., Avolio, B.J., Norman, S.M., \& Combs, G.M. (2006). Psychological capital development: Toward a micro-intervention. Journal of Organizational Behavior, 27, 387-393.

Luthans, F., Youssef, C.M., \& Avolio, B.J. (2007). Psychological capital: Developing the human competitive edge. New York: Oxford University Press.

MacKinnon, D.P., Lockwood, C.M., \& Williams, J. (2004). Confidence limits for the indirect effect: Distribution of the product and resampling methods. Multivariate Behavioral Research, 39, 99-128.

Maslach, C. (1993). Burnout: A multidimensional perspective. In W. B. Schaufeli, C. Maslach, \& T. Marek (Eds.), Professional burnout: Recent developments in theory and research (pp. 19-32). Washington, DC: Taylor \& Francis.

Maslach, C., \& Jackson, S.E. (1981). The measurement of experienced burnout. Journal of Occupational Behavior, 2, 99-113.

McCarthy, J.M., Trougakos, J.P., \& Cheng, B.H. (2016). Are anxious workers less productive workers? It depends on the quality of social exchange. Journal of Applied Psychology, 101, 279-291. 
Mulki, J.P., Jaramillo, F., Locander, W.B. (2006). Emotional exhaustion and organizational deviance: Can the right job and a leader's style make a difference? Journal of Business Research, 59, 1222-1230.

Naseer, S., Raja, U., Syed, F., Donia, M.B.L., \& Darr, W. (2016). Perils of being close to a bad leader in a bad environment: Exploring the combined effects of despotic leadership, leader member exchange, and perceived organizational politics on behaviors. Leadership Quarterly, 27, 14-33.

Organ, D. W. (1988). Organizational citizenship behavior: The good soldier syndrome. Lexington, MA: Lexington Books.

Ormond, W.E., Keown-Gerrard, J.L., \& Kline, T. (2003). Stress audits as a precursor to stress management workshops: An evaluation of the process. Human Resource Development Quarterly, 14, 111-116.

Peterson, S.J., \& Luthans, F. (2003). The positive impact and development of hopeful leaders. Leadership \& Organization Development Journal, 24, 26-31.

Podsakoff, P.M., MacKenzie, S.B., Paine, J.B., \& Bachrach, D.G. (2000). Organizational citizenship behaviors: A critical review of the theoretical and empirical literature and suggestions for future research. Journal of Management, 26, 513-563.

Podsakoff, N. P., Whiting, S. W., Podsakoff, P. M., \& Blume, B. D. (2009). Individual-and organizational-level consequences of organizational citizenship behaviors: A meta-analysis. Journal of Applied Psychology, 94, 122-141.

Pooja, A.A., De Clercq, D., \& Belausteguigoitia, I. (2016). Job stressors and organizational citizenship behavior: The roles of organizational commitment and social interaction. Human Resource Development Quarterly, 27, 373-405.

Preacher, K. J., Rucker, D. D., \& Hayes, A. F. (2007). Assessing moderated mediation hypotheses: Theory, methods, and prescriptions. Multivariate Behavioral Research, 42, 185227.

Priesemuth, M., \& Taylor, R.M. (2016). The more I want, the less I have left to give: The moderating role of psychological entitlement on the relationship between psychological contract violation, depressive mood states, and citizenship behavior. Journal of Organizational Behavior, 37, 967-982.

Quinn, R.W., Spreitzer, G.M., \& Lam, C.F. (2012). Building a sustainable model of human energy in organizations: Exploring the critical role of resources. Academy of Management Annals, 6, 337-396.

Raja, U., \& Johns, G. (2010). The joint effects of personality and job scope on in-role performance, citizenship behaviors, and creativity. Human Relations, 63, 985-1007.

Rego, A., Machado, F., Leal, S., \& Cunha, M.P. (2009). Are hopeful employees more creative? An empirical study. Creativity Research Journal, 21, 223-231.

Rego, A., Marques, C., Leal, S., Sousa, F., \& Cunha, M.P. (2010). Psychological capital and performance of Portuguese civil servants: Exploring neutralizers in the context of an appraisal system. International Journal of Human Resource Management, 21, 1531-1552

Rego, A., Sousa, F., Marques, C., \& Cunha, M.P. (2012). Retail employees’ self-efficacy and hope predicting their positive affect and creativity. European Journal of Work and Organizational Psychology, 21, 923-945.

Rodell, J. B. \& Judge, T. A. (2009). Can good stressors spark bad behaviors? The mediating role of emotions in links of challenge and hindrance stressors with citizenship and counterproductive behaviors. Journal of Applied Psychology, 94, 1438-1451. 
Rurkkhum, S., \& Bartlett, K.R. (2012). The relationship between employee engagement and organizational citizenship behaviour in Thailand. Human Resource Development International, 15, 157-174.

Ryan, R.M., \& Deci, E.L. (2000). Self-determination theory and the facilitation of intrinsic motivation, social development, and well-being. American Psychologist, 55(1): 68-78.

Sassi, N., El Akremi, A., \& Vandenberghe, C. (2015). Examining the frustration-aggression model among Tunisian blue-collar workers. Journal of Managerial Psychology, 30, 336-353.

Snyder, C.R. (2000). The past and future of hope. Journal of Social and Clinical Psychology, 19, 11-28.

Snyder, C.R., Irving, L.M., \& Anderson, J.R. (1991). Hope and health. In C.R. Snyder (Ed.), Handbook of social and clinical psychology (pp. 295-305). Oxford: Oxford University Press.

Snyder, C.R., Lapointe, A.B., Crowson, J.J. Jr., \& Early, S. (1998). Preferences of high- and low-hope people for self-referential input. Cognition and Emotion, 12, 807-823.

Snyder, C.R., Rand, K.L., \& Sigmon, D.R. (2002). Hope theory: A member of the positive psychology family. In C. R. Snyder, \& S. Lopez (Eds.), Handbook of positive psychology (pp. 257-266). New York: Oxford University Press.

Sommer, K.L. \& Kulkarni, M. (2012). Does constructive performance feedback improve citizenship intentions and job satisfaction? The roles of perceived opportunities for advancement, respect, and mood. Human Resource Development Quarterly, 23, 177-201.

Spector, P. E. (2006). Method variance in organizational research: Truth or urban legend? Organizational Research Methods, 9, 221-232.

Spitzmuller, M., Van Dyne, L., \& Ilies, R. (2008). Organizational citizenship behavior: A review and extension of its nomological network. In J. Barling \& C.L. Cooper (Eds.), The SAGE Handbook of Organizational Behavior (Vol. 1, pp. 106-123). Thousand Oaks, CA: Sage.

ten Brummelhuis, L.L., \& van der Lippe, T. (2010). Effective work-life balance support for various household structures. Human Resource Management, 49(2), 173-193

Tierney, P., \& Farmer, S.M. (2002). Creative self-efficacy: Potential antecedents and relationship to creative performance. Academy of Management Journal, 45, 1137-1148.

Trougakos, J.P., Beal, D.J., Cheng, B.H., Hideg, I., \& Zweig, D. (2015). Too drained to help: A resource depletion perspective on daily interpersonal citizenship behaviors. Journal of Applied Psychology, 100, 227-236.

Valle, M.F., Huebner, E.S., \& Suldo, S.M. (2006). An analysis of hope as a psychological strength. Journal of School Psychology, 44, 393-406.

Vigoda-Gadot, E., \& Grimland, S. (2008). Values and career choice at the beginning of the MBA educational process. Career Development International, 13, 333-345.

Walsh, G., Dahling, J.J., Schaarschmidt, M., \& Brach, S. (2016). Surface-acting outcomes among service employees with two jobs: Investigating moderation and mediation effects. Journal of Service Management, 27, 534-562.

Williams, L.J., \& Anderson, S. E. 1991. Job satisfaction and organizational commitment as predictors of organizational citizenship and in-role behavior. Journal of Management, 17, 601-617.

Witt, L.A., \& Carlson, D.S. (2006). The work-family interface and job performance: Moderating effects of conscientiousness and perceived organizational support. Journal of Occupational Health Psychology, 11, 343-357.

Wright, T.A., \& Cropanzano, R. (1998). Emotional exhaustion as a predictor of job performance and voluntary turnover. Journal of Applied Psychology, 83, 486-493. 
Zhang, M., Griffeth, R.W., \& Fried, D.D. (2012). Work-family conflict and individual consequences. Journal of Managerial Psychology, 27(7), 696-713. 
Figure 1. Conceptual model




Figure 2: Moderating effect of waypower on the relationship between family incivility and emotional exhaustion

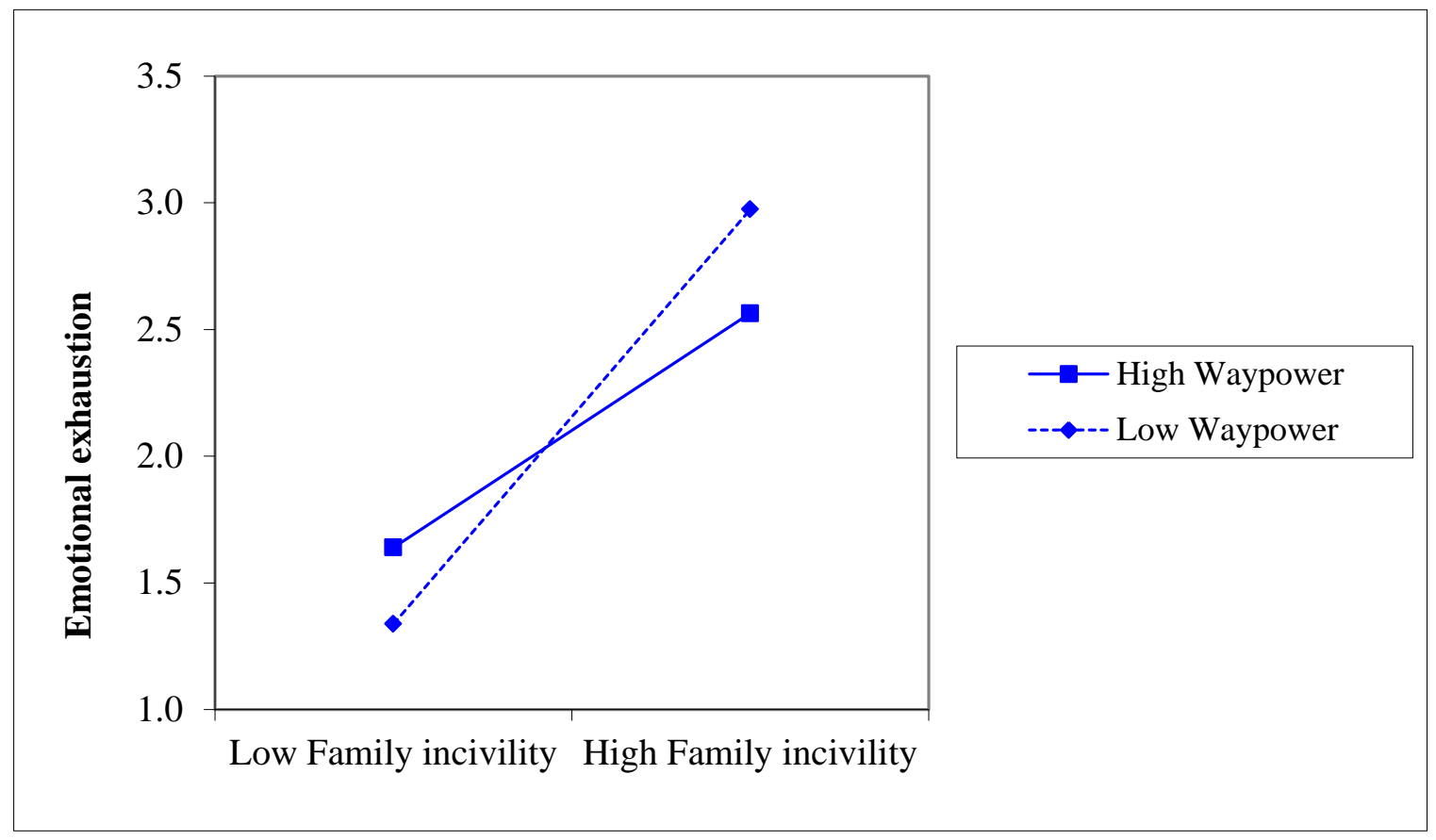


Figure 3: Moderating effect of willpower on the relationship between family incivility and emotional exhaustion

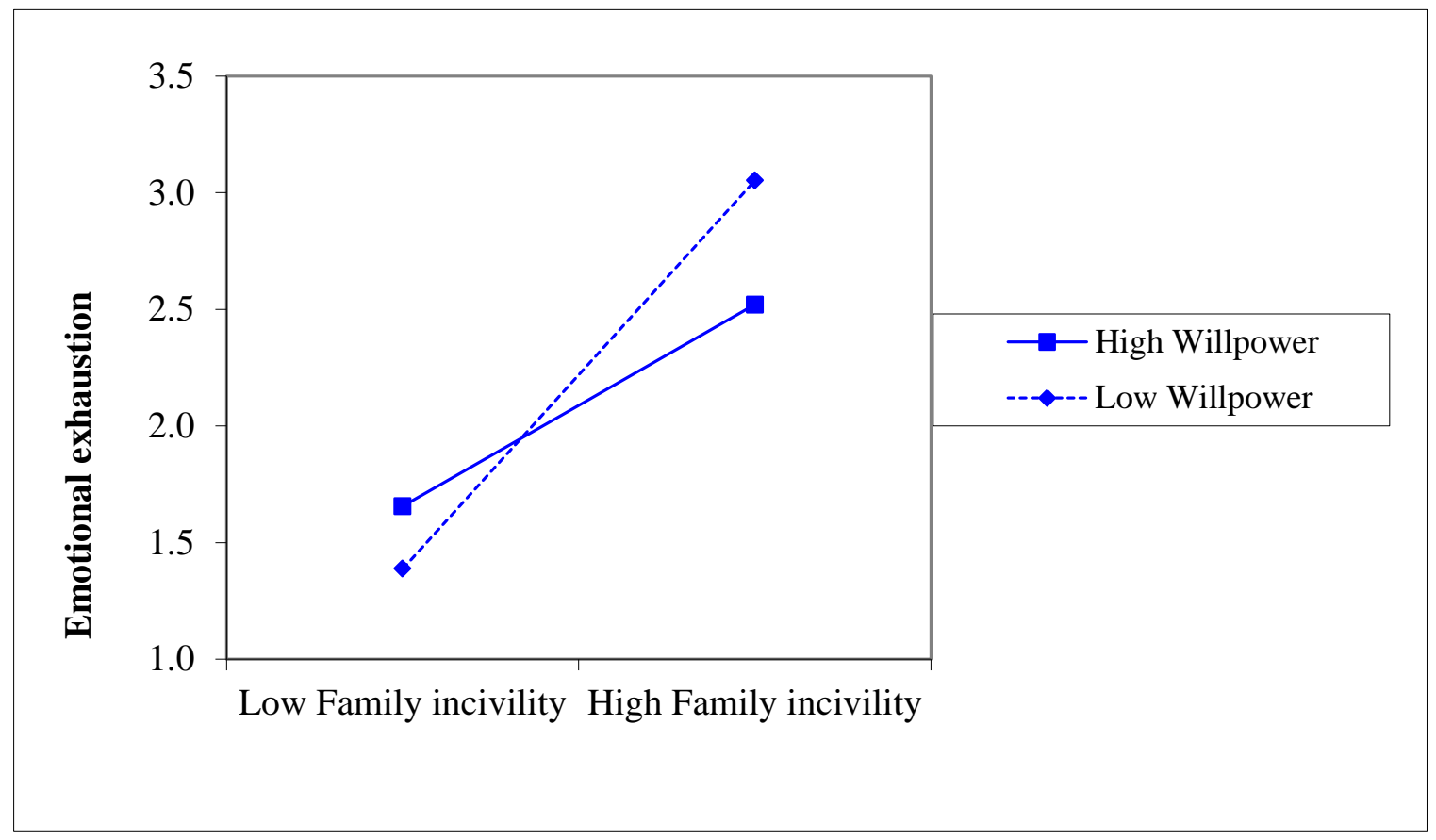


Table 1. Exploratory factor analysis for waypower and willpower

\section{Factor 1}

\section{Waypower}

If I find myself troubled at work, I can think of many ways to overcome it.

There are lots of ways around any problem.

I can think of many ways to reach my current work goals.

Willpower

At the present time, I am energetically pursuing my work goals.

At this time, I am meeting the work goals that I have set for myself.

Right now I see myself as being pretty successful at work.

$$
\text { Eigenvalue }
$$

Variance explained

Note: $\mathrm{n}=210$; factor loadings are reported.

\section{Factor 2}

.18

.13

.27

.80

.70

.83

.24

.85

2.00

$33.40 \%$ 
Table 2. Correlations and descriptive statistics

\begin{tabular}{|c|c|c|c|c|c|c|c|c|c|c|}
\hline & 1 & 2 & 3 & 4 & 5 & 6 & 7 & 8 & 9 & 10 \\
\hline 1. OCB & $(.73)$ & & & & & & & & & \\
\hline 2. Emotional exhaustion & $-.32 * *$ & $(.93)$ & & & & & & & & \\
\hline 3. Family incivility & -.11 & $.49 * *$ & $(.83)$ & & & & & & & \\
\hline 4. Waypower & $.20 * *$ & $-.27 * *$ & $-.22 * *$ & $(.80)$ & & & & & & \\
\hline 5. Willpower & .12 & $-.27 * *$ & $-.23 * *$ & $.47 * *$ & $(.76)$ & & & & & \\
\hline 6. Gender ( 1 = female) & $.33 * *$ & $-.30 * *$ & $-.19 * *$ & $.15^{*}$ & $.18^{*}$ & -- & & & & \\
\hline 7. Married & -.05 & -.07 & -.05 & .08 & .11 & $-.19 * *$ & -- & & & \\
\hline 8. Joined family & .01 & -.02 & -.10 & -.11 & .01 & $.21^{* *}$ & -.02 & -- & & \\
\hline 9. Education & $.36 * *$ & $-.33 * *$ & $-.17 *$ & $.23 * *$ & $.14^{*}$ & $.38 * *$ & .11 & $.18^{*}$ & -- & \\
\hline 10. Organizational tenure & .05 & -.04 & -.02 & -.10 & .00 & $-.23 * *$ & $.36 * *$ & .08 & -.01 & -- \\
\hline Mean & 5.45 & 1.88 & 2.00 & 4.64 & 4.47 & .34 & .47 & .43 & 2.10 & 4.52 \\
\hline Standard deviation & .99 & 1.44 & .96 & 1.17 & 1.13 & .47 & .50 & .50 & .87 & 5.48 \\
\hline
\end{tabular}

Notes: $\mathrm{n}=210$; Cronbach's alphas are reported in parentheses, on the diagonal.

$* p<.05$.

$* * p<.01$. 
Table 3. Regression results

\begin{tabular}{|c|c|c|c|c|c|c|c|}
\hline & \multicolumn{4}{|c|}{ Emotional exhaustion } & \multicolumn{3}{|c|}{$\mathrm{OCB}$} \\
\hline & Model 1 & Model 2 & Model 3 & Model 4 & Model 5 & Model 6 & Model 7 \\
\hline Gender (1 = female) & $-.78 * * *$ & $-.50 *$ & $-.46 *$ & $-.48 *$ & $.54 * * *$ & $.52 * * *$ & $.45^{* *}$ \\
\hline Married & -.16 & -.03 & -.02 & -.03 & -.17 & -.20 & -.20 \\
\hline Joined family & .24 & .26 & .20 & .23 & -.21 & -.17 & -.14 \\
\hline Education & $-.39 * * *$ & $-.30 * *$ & $-.28 * *$ & $-.29 * *$ & $.33 * * *$ & $.30 * * *$ & $.26 * *$ \\
\hline Organizational tenure & -.02 & -.02 & -.02 & -.02 & $.03 *$ & $.03^{*}$ & $.03^{*}$ \\
\hline Family incivility & & $.61 * * *$ & $.64^{* * *}$ & $.63 * * *$ & & -.01 & .08 \\
\hline Waypower & & -.09 & -.03 & -.12 & & .10 & .09 \\
\hline Willpower & & -.11 & $-.15^{+}$ & -.07 & & -.01 & -.02 \\
\hline Family incivility $\times$ Waypower & & & $-.18^{*}$ & & & & \\
\hline Family incivility $\times$ Willpower & & & & $-.20 * *$ & & & \\
\hline Emotional exhaustion & & & & & & & $-.14^{* *}$ \\
\hline $\mathrm{R}^{2}$ & .16 & .36 & .37 & .38 & .20 & .21 & .24 \\
\hline$\Delta \mathrm{R}^{2}$ & & $.20 * * *$ & $.01 *$ & $.02 * *$ & & .01 & $.03^{* *}$ \\
\hline $\begin{array}{l}\text { Notes: } \mathrm{n}=210 . \\
{ }^{+} p<.10 \\
* p<.05 \\
* * p<.01 \\
* * * p<.001\end{array}$ & & & & & & & \\
\hline
\end{tabular}

